\title{
Oxymatrine inhibits the migration of human colorectal carcinoma RKO cells via inhibition of PAI-1 and the TGF-ß1/Smad signaling pathway
}

\author{
XIAOYU WANG ${ }^{1}$, CHUN LIU $^{1}$, JIAQI WANG ${ }^{2}$, YUE FAN $^{3}$, ZHENGHUA WANG $^{4}$ and YUANYUAN WANG ${ }^{4}$ \\ ${ }^{1}$ Department of Biochemistry, Liaoning University of Traditional Chinese Medicine, Shenyang, Liaoning 110001; \\ Departments of ${ }^{2}$ Traditional Chinese Medicine, ${ }^{3}$ Human Resources and ${ }^{4}$ Oncology (Third Ward), \\ The First Affiliated Hospital of Jinzhou Medical University, Jinzhou, Liaoning 121001, P.R. China
}

Received June 15, 2016; Accepted July 28, 2016

DOI: $10.3892 /$ or.2016.5292

\begin{abstract}
Transforming growth factor- $\beta 1$ (TGF- $\beta 1$ ) signaling has been shown to play a critical role in the development of epithelial-mesenchymal transition (EMT). PAI-1 is one of the most important target genes in the TGF- $\beta /$ Smad signaling pathway, which can hinder the degradation of ECM composition and may promote cell invasion and migration. Oxymatrine $(\mathrm{OM})$ is an alkaloid extracted from the Chinese herb Sophora flavescens Ait and has been demonstrated to inhibit the growth of various types of cancer cells including colorectal cancer. However, the anticancer effect of OM in colorectal cancer remains unclear. In the present study, we detected the expression of E-cadherin, $\alpha$-SMA, FN, TGF- $\beta 1$, PAI-1, Smad4, pP38 and pSmad2 in FHC, RKO and OM-treated RKO cells. We also detected pSmad 2 and PAI-1 in RKO cells following the addition of SB203580 (a p38 MAPK inhibitor). The results showed that E-cadherin expression in RKO cells was significantly decreased, while PAI- 1, TGF- $\beta 1, \alpha$-SMA, FN, Smad4, pSmad2 and pP38 expression levels were significantly increased in the RKO cells compared to levels in the FHC cells, which was almost completely reversed by OM. OM alleviated EMT induced in colorectal cancer via inhibition of TGF- $\beta 1 /$ Smad signaling pathway activation by reducing P38-dependent increased expression of PAI-1. Hence, OM could be a novel therapeutic agent for colorectal cancer.
\end{abstract}

\section{Introduction}

Oxymatrine (OM) (structure shown in Fig. 1) is the principal component of Sophora flavescens Ait, which is frequently prescribed in traditional Chinese medicine. OM has been

Correspondence to: Dr Chun Liu, Department of Biochemistry, Liaoning University of Traditional Chinese Medicine, 79 Chongshan Eastern Road, Huanggu, Shenyang, Liaoning 110001, P.R. China

E-mail: liuchun_52@sina.com

Key words: TGF- $\beta 1$, EMT, PAI-1, colorectal cancer, RKO cells, FHC cells reported to have immune regulation, anti-inflammatory and diuretic effects (1-6). Moreover, OM inhibits the growth of various types of cancer cells (7-9). Although there are some studies in regards to OM concerning the inhibition of malignant tumor cell growth, studies concerning the molecular mechanisms, signaling pathways, invasion and metastasis of the anticancer effects of $\mathrm{OM}$ are rare.

Colorectal carcinoma is one of the most common malignant tumors (10). Invasion and metastasis are fundamental properties of malignant colon cancer, which lead to a high recurrence rate after surgery and therapeutic approaches (11). In the process of tumor metastasis, epithelial-mesenchymal transition (EMT) is a key mediator (12). The molecular mechanisms of EMT involved in tumor metastasis remain unclear, and current treatments have limited effectiveness. Thus, in order to develop new effective therapeutic measures for colon cancer, further investigation of its molecular mechanisms is required.

Plasminogen activator inhibitor 1 (PAI-1) is a rapid and specific inhibitor of the plasminogen/plasmin system (13). In recent years, studies have demonstrated that PAI-1 is a potent regulator of tumor growth in vivo. Increased PAI-1 has been confirmed in many solid tumor types and was found to be associated with a poor prognosis (14-16). Thus, PAI-1 is regarded as a biochemical marker for poor prognosis and may serve as a therapeutic target for various types of cancers. There is evidence that plasma PAI- 1 is closely correlated with rectal cancer metastasis, and tumor tissue PAI-1 is associated with the histopathology and outcome of rectal cancer (17). Whether PAI-1 may serve as a target in the antitumor therapy of colorectal carcinoma remains unclear.

EMT is a process by which epithelial cells lose their orientation and cell-cell contact, and acquire migratory and invasive properties of mesenchymal cells. Transforming growth factor- $\beta 1$ (TGF- $\beta 1$ ) is known as a key mediator of EMT (18). TGF- $\beta 1$ promotes EMT via upregulation of ECM expression and downregulation of transcriptional activity of matrix-degrading enzyme genes. Increasing studies have shown that SBE (Smad binding element) exists in the promoter region of genes, such as PAI-1, regulated by TGF- $\beta$ (19). SBE in the promoter region of these genes combines directly or indirectly with the Smad complex. PAI-1 is one of the most 
important target genes in the TGF- $\beta /$ Smad signaling pathway, which can hinder the degradation of ECM composition and may promote cell invasion and migration (20). It is unclear how TGF- $\beta /$ Smad controls PAI-1 in colorectal cancer and the relation between PAI-1 and colorectal cancer.

In the present study, we investigated the anti-metastatic and anti-invasive effects of OM in RKO cells. Simultaneously we detected the effects of OM on the TGF- $\beta 1 /$ Smad signaling pathway and PAI-1 in RKO cells to investigate the underlying signaling molecular mechanisms by which OM inhibits the invasion and metastasis of RKO cells.

\section{Materials and methods}

Reagents and medicine. OM was obtained from National Institutes for Food and Drug Control (Beijing, China). The relative molecular mass of $\mathrm{OM}$ is 264.367, and the molecular structural formula is $\mathrm{C}_{15} \mathrm{H}_{24} \mathrm{~N}_{2} \mathrm{O}_{2}$. The purity of OM was determined by high-performance liquid chromatography (HPLC) as $98 \%$. OM, a colorless columnar crystal, was dissolved in PBS and prepared for $20 \mathrm{mg} / \mathrm{ml}$ mother solution. The solution was stored at $-20^{\circ} \mathrm{C}$ in a refrigerator and stored away from light. Serum-free and antibiotic-free RPMI-1640 medium was diluted to the required concentration. $\mathrm{OM}$ was diluted to the required concentration by serum-free and antibiotic-free RPMI-1640 medium for use.

TRIzol reagent (Invitrogen, Carlsbad, CA, USA), GoScript $^{\mathrm{TM}}$ Reverse Transcription system kit (Promega, Madison, WI, USA), Matrigel (BD Biosciences Inc., Franklin Lakes, NJ, USA), Cell Counting Kit-8 (ATCC Biosciences Center, USA), RIPA buffer (Kaiji Biotechnology, Shanghai, China), PVDF membranes (Millipore, Billerica, MA, USA) primary E-cadherin antibody (rabbit, 1:400, Santa Cruz Biotechnology, Inc., Santa Cruz, CA, USA), $\alpha$-SMA antibody (mouse, 1:400, Sigma-Aldrich, St. Louis, MO, USA), FN antibody (goat, 1:150, Santa Cruz Biotechnology, Inc.), TGF- $\beta 1$ antibody (mouse, 1:200, Santa Cruz Biotechnology, Inc.), antiSmad4 antibody (rabbit, 1:1000, Atlas, Sweden), anti-PAI-1 antibody (rabbit, 1:1000, American Research Products Inc., Grandville, MI, USA), phospho-p38 (pP38) MAPK (Tyr182) antibody (rabbit, 1:1000, Affinity Biosciences, Cincinnati, $\mathrm{OH}, \mathrm{USA}$ ), $\beta$-actin antibody (mouse, 1:400, Santa Cruz Biotechnology, Inc.), phospho-Smad2 (pSmad2) antibody (Ser465/467) (rabbit, 1:150, Cell Signaling Technology, Inc., Danvers, MA, USA), and horseradish peroxidase-conjugated secondary antibodies (1:5000, Santa Cruz Biotechnology, Inc.) were procured for the experiments. All chemicals were purchased in the purest form available.

Cell culture. Colorectal carcinoma RKO cells, obtained from ATCC Biosciences Center, were grown in RPMI-1640 medium supplemented with $10 \%$ heat-inactivated fetal bovine serum (FBS; Gibco, Carlsbad, CA, USA), $100 \mu \mathrm{g} / \mathrm{ml}$ streptomycin and $100 \mathrm{U} / \mathrm{ml}$ penicillin in a humidified atmosphere containing $5 \% \mathrm{CO}_{2}$ at $37^{\circ} \mathrm{C}$. Cells grew as a single cell layer attached to specially treated plastic surfaces. The human fetal colon FHC cell line was cultured in basal medium (cat. no. 30-2006) supplemented with $10 \mathrm{mM}$ HEPES, $10 \mathrm{ng} / \mathrm{ml}$ cholera toxin, $0.005 \mathrm{mg} / \mathrm{ml}$ insulin, $0.005 \mathrm{mg} / \mathrm{ml}$ transferrin, $100 \mathrm{ng} /$ $\mathrm{ml}$ hydrocortisone and $10 \%$ fetal bovine serum. In order to

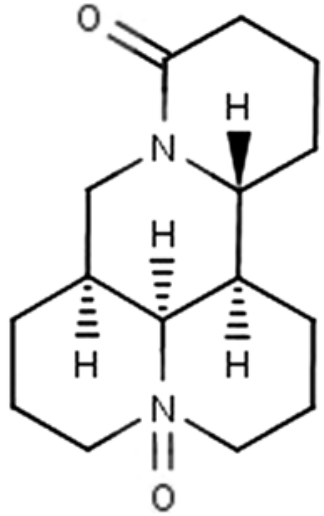

Figure 1. Chemical structure of oxymatrine (OM).

maintain the viability and active growth of adherent cells, it is necessary to subculture them at regular intervals ( 2 or 3 times a week). Cells during an exponential growth phase were used in the experiments. However, in the invasion and migration experiments, the cells were cultured in a serum-free medium. The cells were randomly divided into three groups: FHC cell control group (FHC group), untreated RKO cell group (UR group), and OM-treated RKO cell group (OR group).

Cell Counting Kit- 8 assay. The antiproliferative effects of different concentrations of OM on the RKO cell line were detected by CCK- 8 assay. Cells were seeded at a density of $1 \times 10^{4}$ per well in $100 \mu \mathrm{l}$ of RPMI-1640 medium with $10 \%$ FBS in 96-well plates. On the next day, the medium was replaced with serum-free RPMI-1640 with OM (from 0-20 mg/ml) for the RKO cells. Each concentration was used in 4 wells. After incubation for $24,48,72 \mathrm{~h}$ in a humidified atmosphere containing $5 \% \mathrm{CO}_{2}$ at $37^{\circ} \mathrm{C}$, respectively, $10 \mu \mathrm{l} \mathrm{CCK}(5 \mathrm{mg} / \mathrm{l})$ was added each well, and the plates were incubated for an additional $4 \mathrm{~h}$. Then the medium was discarded, and the absorbance (A) of the CCK-8 solution was determined at $450 \mathrm{~nm}$ using a multiwell spectrophotometer (Bio-Tek Instruments, XL-808, Winooski, VT, USA). The proliferation rate of the cells was calculated as follows: Proliferation rate $(\%)=\mathrm{A}$ of the treated wells/A of the control wells (OM $0 \mathrm{mg} / \mathrm{ml}) \times 100$. The assay was performed in triplicate.

Wound healing assay. The cells were seeded into 6-well plates and when the cells were grown to confluency, a wound was created by manually scraping the cells with a pipette tip. Debris was removed from the culture by washing it twice with PBS. Then the cells were incubated with serum-free medium to exclude the effect of cell growth facilitated by serum and the cells were then allowed to migrate into the wounded area at $37^{\circ} \mathrm{C}$. Images were immediately acquired at 0 and $24 \mathrm{~h}$ after wounding and measured using Image-Pro Plus 6.0 software. The cell migration rate $(\%)=$ (wound width at $0 \mathrm{~h}$ - wound width at $24 \mathrm{~h}$ )/wound width at $0 \mathrm{~h} \times 100$. The assay was performed in triplicate.

Western blot analysis. Cells were plated onto culture flasks at a density of $2 \times 10^{5}$ cells $/ \mathrm{ml}$ and cultured at $37^{\circ} \mathrm{C}$ in $5 \%$ $\mathrm{CO}_{2}$. On the next day, different concentrations of OM $(0$, 


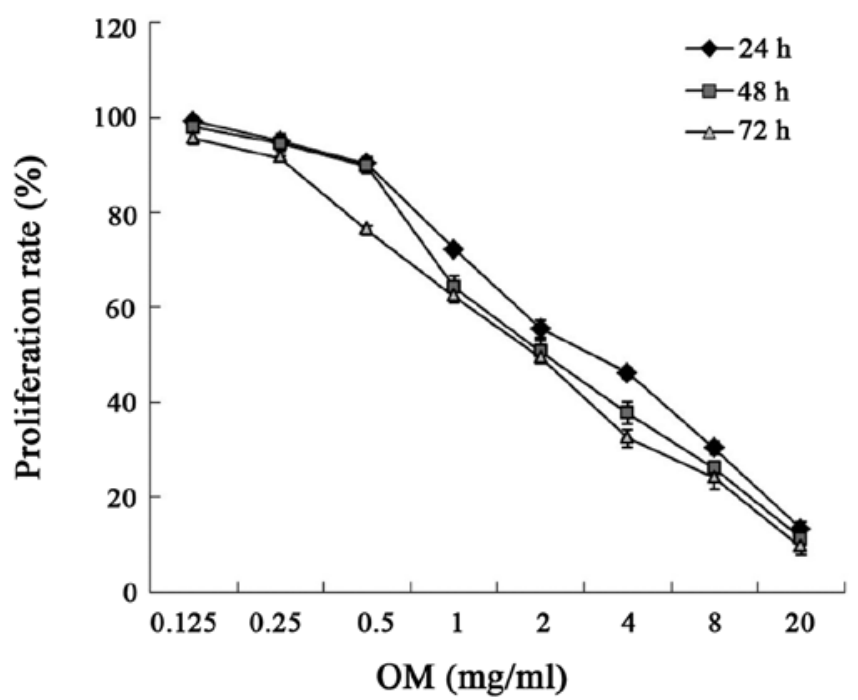

Figure 2. Effects of oxymatrine (OM) on the proliferation of RKO cells. Cells were treated with different concentrations of OM for 24, 48 and $72 \mathrm{~h}$. The absorbance (A) of the CCK- 8 solution was determined at $450 \mathrm{~nm}$. Proliferation rates of different concentrations OM were calculated. The experiments were performed in triplicate.

$0.25,0.5,1$ and $2 \mathrm{mg} / \mathrm{ml}$ ) were added. After $24 \mathrm{~h}$, the levels of proteins were quantified through western blot analysis. Proteins were extracted by the addition of $200 \mu \mathrm{l}$ of lysis buffer [50 mmol/1 Tris-HCl (pH 7.4), 5 mmol/1 EDTA, 1\% Triton X-100, $150 \mathrm{mmol} / \mathrm{l} \mathrm{NaCl}, 5 \mathrm{mmol} / 1 \mathrm{MgCl}_{2}, 2 \mathrm{mmol} / \mathrm{l}$ $\mathrm{Na}_{3} \mathrm{VO}_{4}, 1 \mathrm{X}$ Complete ${ }^{\mathrm{TM}}$ protease inhibitor] to each well. The cell lysates were incubated on ice for $30 \mathrm{~min}$ vortexing every $10 \mathrm{~min}$, followed by centrifugation at $12000 \mathrm{x}$ g for $30 \mathrm{~min}$ at $4^{\circ} \mathrm{C}$. An amount $40 \mu \mathrm{g} / \mu \mathrm{l}$ of protein of the cell lysate was mixed equally with $2 \mathrm{X}$ electrophoresis buffer [50\% glycerol, $25 \%$ mercaptoethanol, $10 \%$ SDS, 0.3 M Tris (pH 6.8), $0.025 \%$ bromphenol blue] and boiled for $10 \mathrm{~min}$. The samples $(40 \mu \mathrm{g}$ of protein) of total cell lysates were separated by sodium dodecyl sulfate-polyacrylamide gel electrophoresis at $75 \mathrm{~V}$ (the voltage was changed to $100 \mathrm{~V}$ when the indicator reached $1.5 \mathrm{~cm}$ from the edge of the $10 \%$ separation gel) and electrophoretically transferred onto a polyvinylidene difluoride membrane (Millipore) in transfer buffer containing $25 \mathrm{mM}$ Tris, $150 \mathrm{mM}$ glycine and $20 \%$ methanol. The membranes were blocked using $5 \%$ skim milk at $37^{\circ} \mathrm{C}$ for $2 \mathrm{~h}$. The membranes were then incubated with primary antibodies for 16-18 h at $4^{\circ} \mathrm{C}$. The membranes were washed in $1 \mathrm{X}$ TBST 3 times (10 min each time) at room temperature. The membranes were subsequently probed with an anti-rabbit IgG antibody with the HRP-conjugated secondary antibody (1:1000) for $2 \mathrm{~h}$. Control blots were performed using anti-actin antibodies. The membranes were washed in 1X TBST for 3 times (10 min each time) at room temperature, and detection was achieved by measuring the chemiluminescence of the blotting agent after exposure of the filters to X-omat films. The densities of the bands were quantified using a computerized densitometer (ImageJ Launcher, Broken Symmetry Software).

Reverse transcription PCR. Different concentrations of OM ( 0 , $0.25,0.5,1$ and $2 \mathrm{mg} / \mathrm{ml}$ ) were added into the cells, respectively. After $24 \mathrm{~h}$, the levels of mRNA were quantified through reverse
Table I. Effects of OM on the proliferation of RKO cells.

\begin{tabular}{|c|c|c|c|}
\hline & \multicolumn{3}{|c|}{ Proliferation rate $(\%)$} \\
\hline & $24 \mathrm{~h}$ & $48 \mathrm{~h}$ & $72 \mathrm{~h}$ \\
\hline \multicolumn{4}{|l|}{$\mathrm{OM}(\mathrm{mg} / \mathrm{ml})$} \\
\hline 0.125 & $99.209 \pm 0.492$ & $97.944 \pm 0.955$ & $95.598 \pm 1.129$ \\
\hline 0.25 & $95.089 \pm 1.384$ & $94.621 \pm 1.737$ & $91.490 \pm 0.462$ \\
\hline 0.5 & $90.261 \pm 1.331$ & $89.766 \pm 1.599^{\mathrm{a}}$ & $76.267 \pm 0.987^{a}$ \\
\hline 1 & $72.223 \pm 0.990^{\mathrm{a}}$ & $64.231 \pm 2.406^{\mathrm{a}}$ & $62.221 \pm 1.361^{\mathrm{a}}$ \\
\hline 2 & $55.446 \pm 1.842^{\mathrm{a}}$ & $50.662 \pm 2.393^{\mathrm{a}}$ & $49.359 \pm 0.309^{a}$ \\
\hline 4 & $46.207 \pm 1.098^{\mathrm{a}}$ & $37.748 \pm 2.385^{\mathrm{a}}$ & $32.431 \pm 1.866^{\mathrm{a}}$ \\
\hline 8 & $0.320 \pm 1.329^{a}$ & $26.146 \pm 1.293^{\mathrm{a}}$ & $24.051 \pm 2.362^{\mathrm{a}}$ \\
\hline 20 & $30.366 \pm 1.520^{\mathrm{a}}$ & $11.265 \pm 1.341^{\mathrm{a}}$ & $9.469 \pm 1.550^{\mathrm{a}}$ \\
\hline
\end{tabular}

${ }^{\mathrm{a}} \mathrm{P}<0.05$ vs. the control group (OM $\left.0 \mathrm{mg} / \mathrm{ml}\right)$.

transcription-PCR (RT-PCR). RNA was isolated from the treated RKO cells using TRIzol reagent. Following the manufacturer's protocol, cDNA was generated from the total RNA using the GoScript ${ }^{\mathrm{TM}}$ Reverse Transcription system kit. Subsequently, PCR was conducted using the following primer sequences: sense primer: $\beta$-actin (used as the input control), forward primer, 5'-ACCACCATGTACCCAGGCAT-3' and reverse primer 5'-CCGGACTCATCGTACTCCTG-3'; TGF- $\beta 1$ (400 bp NM 021578.2), forward primer 5'-AAGGCTCGCCAG TCCCCCGA-3' and reverse primer 5'-AGTGGGGGTCAG CAGCCGT-3'; PAI (1400 bp), forward primer 5'-CGGAGC ACGGTCAAGCAAGTG-3' and reverse primer 5'-GGTGAG GGCAGAGAGAGGCAC-3'. Reaction conditions consisted of: $95^{\circ} \mathrm{C}$ for $5 \mathrm{~min}$ (initial denaturation), followed by 35 cycles of $95^{\circ} \mathrm{C}$ for $30 \mathrm{sec}, 58^{\circ} \mathrm{C}$ for $60 \mathrm{sec}$ and $72^{\circ} \mathrm{C}$ for $60 \mathrm{sec}$. This was followed by a final 8 -min extension period at $72^{\circ} \mathrm{C}$. The $5 \mu \mathrm{l}$ amplified fragments, to which $1 \mu 16 \mathrm{X}$ loading buffer was added, were visualized on $1.5 \%$ agarose gel electrophoresis at $120 \mathrm{~V}$ for $20 \mathrm{~min}$. The results were investigated under a transilluminator. The PCR product was subjected to electrophoresis and the absorbance (A) was analyzed by gel imaging and an analysis system. The relative $m R N A$ level $(\%)=\mathrm{A}$ of the treated PCR product/A of the $\beta$-actin PCR product.

Statistical analysis. All assays were performed in triplicate. Statistical analyses were performed using the SPSS 19.0 software program (SPSS, USA). All data are presented as the mean \pm standard deviation (SD). Statistical differences were determined by the Student's t-test. Statistical significance of differences was accepted at $\mathrm{P}<0.05$.

Statement of ethics. The present study was approved by the Institutional Review Board (CWO) of Liaoning University of Traditional Chinese Medicine.

\section{Results}

Effects of oxymatrine on the proliferation of RKO cells. The cytotoxicity of OM was evaluated using the Cell Counting Kit- 8 assay. As illustrated in Fig. 2 and Table I, after RKO 
A
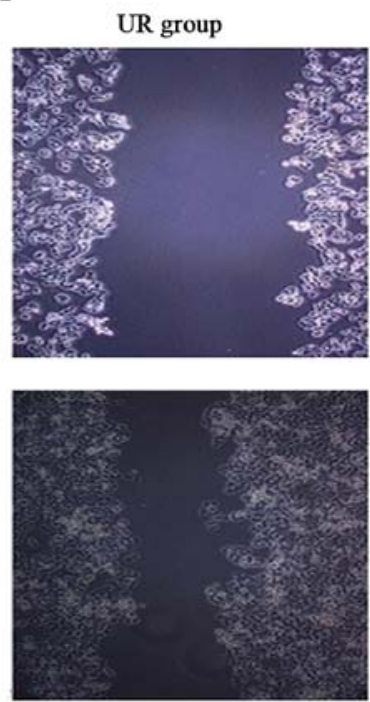

$0.25 \mathrm{mg} / \mathrm{ml}$ OM-treated RKO group
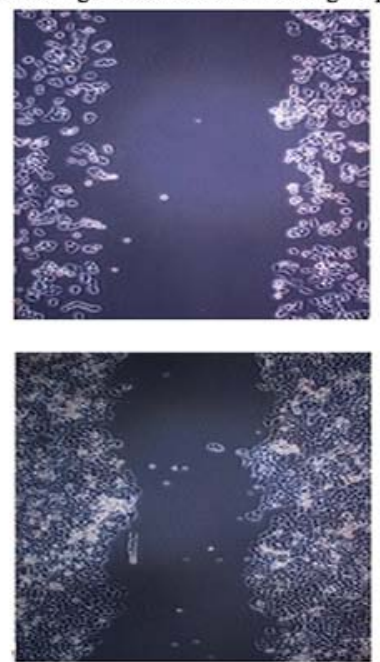

$0.5 \mathrm{mg} / \mathrm{ml}$ OM-treated RKO group
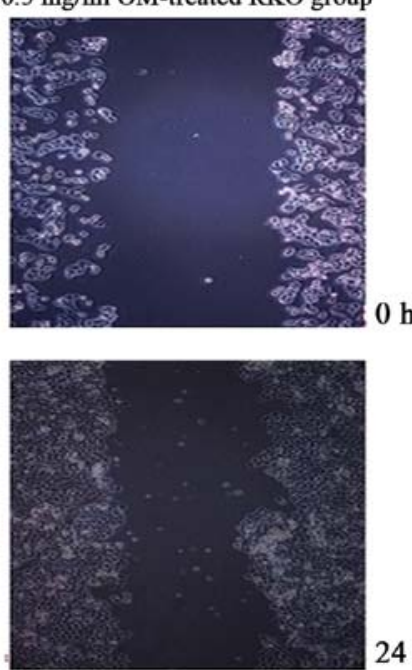

$0 \mathrm{~h}$

$24 \mathrm{~h}$

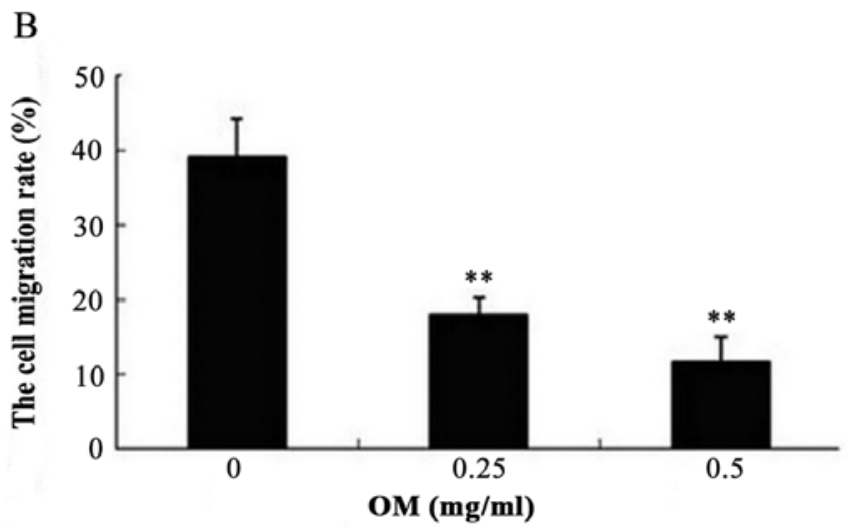

cells were treated with different concentrations of OM for 24, 48 and $72 \mathrm{~h}, \mathrm{OM}$ inhibited the proliferation of the RKO cells in concentration-dependent and time-dependent manner.

OM inhibits the migration of RKO cells. OM was used to examine the effect on the migratory ability of RKO cells by wound healing assay. As a result, treatment of OM obviously reduced the migratory potential of the RKO cells (Fig. 3). The treated cells survived up to 2 days, indicating that the inhibitory changes were not due to the cytotoxic effect of OM. These findings suggest a critical role of $\mathrm{OM}$ in inhibiting the migration of RKO cells.

Effect of OM on the EMT of colorectal cancer cells. To evaluate the effect of OM on RKO cells, the results of the CCK-8 assay, in dose-dependent and time-dependent trials, confirmed that a dose of $0.50 \mathrm{mg} / \mathrm{ml}$ for $24 \mathrm{~h}$ was unlikely to exert a significant toxic effect on the cells. Therefore, $0.50 \mathrm{mg} / \mathrm{ml} \mathrm{OM}$ was used in the subsequent tests. To determine whether OM affected EMT, related marker expression levels of E-cadherin (marker for epithelial cells) and $\alpha$-SMA (marker for mesenchymal cells) were examined by western blotting. The results showed that E-cadherin was significantly reduced and $\alpha$-SMA was markedly increased in the RKO cells as compared to the FHC cells. After the RKO cells were treated with $0.50 \mathrm{mg} / \mathrm{ml}$
Figure 3. Oxymatrine (OM) inhibits the migration of RKO cells. (A) The wound area distances of the UR group, $0.25 \mathrm{mg} / \mathrm{ml} \mathrm{OM-treated} \mathrm{RKO}$ group and $0.5 \mathrm{mg} / \mathrm{ml}$ OM-treated RKO group were $489.876 \pm 12.215$, $480.055 \pm 11.725$ and $487.545 \pm 8.687 \mu \mathrm{m}$ at $0 \mathrm{~h}$, respectively. There was no significant difference $(\mathrm{P}>0.05)$. After $24 \mathrm{~h}$, the wound area distances of the $0.25 \mathrm{mg} / \mathrm{ml} \mathrm{OM}$-treated RKO group and $0.5 \mathrm{mg} / \mathrm{ml} \mathrm{OM}$-treated RKO group were $394.074 \pm 7.032$ and $430.883 \pm 18.028 \mu \mathrm{m}$, respectively, which were obviously wider than the distance of the UR group $(298.662 \pm 18.923 \mu \mathrm{m})$ $(\mathrm{P}<0.05)$. (B) The cell migration rates of the $0.25 \mathrm{mg} / \mathrm{ml} \mathrm{OM}$-treated RKO and $0.5 \mathrm{mg} / \mathrm{ml} \mathrm{OM-treated} \mathrm{RKO} \mathrm{groups} \mathrm{were} 17.88$ and $11.62 \%$, which were obviously lower than the migration rate of the UR group $(38.95 \%){ }^{* *} \mathrm{P}<0.01$.

OM, OM obviously upregulated E-cadherin expression and downregulated $\alpha$-SMA expression (Fig. 4). Taken together, these results demonstrated that OM reversed the EMT process in the colorectal cancer cells.

Effect of OM on fibronectin (FN) in colorectal cancer cells. One key indicator of tumor cell migration is the accumulation of ECM proteins such as FN. EMT mainly leads to the deposition of ECM. To confirm whether OM affects ECM expression, we examined the expression of FN by western blotting, which showed that FN was significantly increased in the RKO cells as compared to the FHC cells. After the RKO cells were treated with $0.50 \mathrm{mg} / \mathrm{ml} \mathrm{OM}$, the expression of FN was significantly decreased in the RKO cells as compared to the untreated control group (Fig. 4). The results suggest that $\mathrm{OM}$ can alleviate the excessive deposition of FN in colorectal cancer.

Effect of OM on the expression of TGF- $\beta 1, P 38$ and PAI-1 in $R K O$ cells. The TGF- $\beta 1 / \mathrm{Smad}$ signaling pathway plays an important role in EMT. P38 promoted the TGF- $\beta 1 / \mathrm{Smad}$ signaling pathway in EMT, suggesting that P38 has an synergistic effect on colorectal cancer. To determine whether OM affects the TGF- $\beta 1 /$ Smad signaling pathway in RKO cells and to investigate the probable molecular mechanisms, we 
A

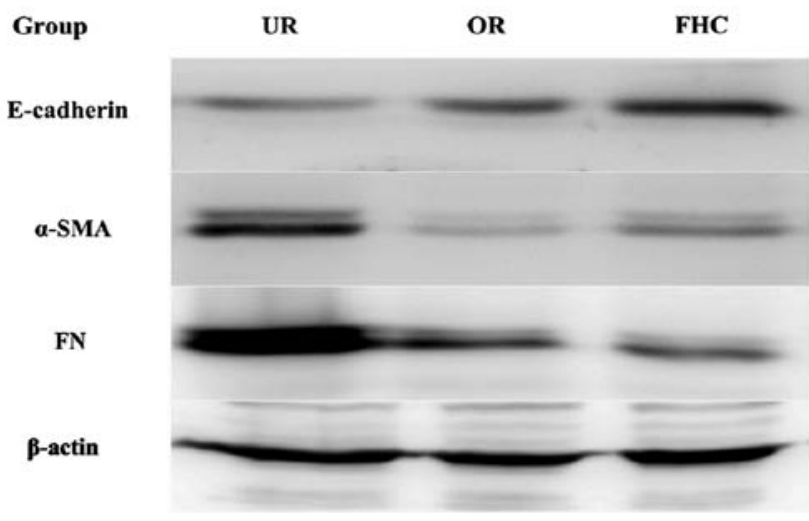

B

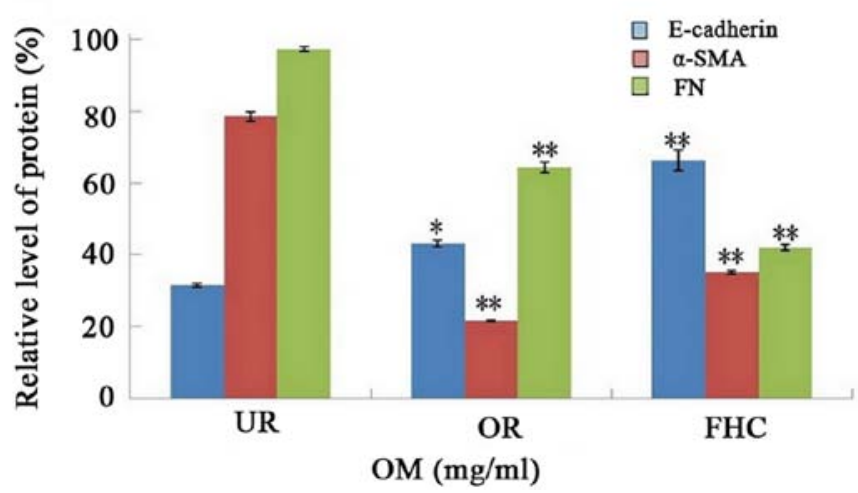

Figure 4. Effect of oxymatrine (OM) on the expression of E-cadherin, $\alpha$-SMA and FN proteins by western blotting. The expression level of E-cadherin was significantly decreased whereas $\alpha$-SMA and FN were markedly increased in the UR group as compared to the FHC group. The expression of E-cadherin was significantly increased while $\alpha$-SMA and FN were significantly decreased in the OR group as compared to the UR group. ${ }^{*} \mathrm{P}<0.05,{ }^{* *} \mathrm{P}<0.01$.

used western blotting and RT-PCR to examine the protein and mRNA expression levels of TGF- $\beta 1$ and PAI- 1 . In addition, Smad4, pSmad 2 and pP38 were detected by western blotting. Western blotting showed that the protein levels of TGF- $\beta 1$, pP38 and PAI- 1 were significantly increased in the RKO cells as compared to the FHC cells. Meanwhile, the protein expression levels of TGF- $\beta 1$ and PAI- 1 were significantly decreased in the OR group as compared to the UR group (Fig. 5). RT-PCR results showed that TGF- $\beta 1$ and PAI-1 mRNA levels were markedly increased in the UR group as compared to the FHC group. After RKO cells were treated with OM, OM was able to decrease TGF- $\beta 1$ and PAI-1 mRNA expression as compared to the UR group (Fig. 6). Of note, the protein levels of Smad2/3/4 and pSmad2 were significantly increased in the RKO cells as compared to the FHC cells, which implied that TGF- $\beta 1$ markedly induced Smad 2 phosphorylation of RKO cells. Meanwhile, the protein levels of Smad2/3/4 and pSmad2 were significantly decreased in the OR group as compared to the UR group, which demonstrated that OM could reverse Smad2 phosphorylation via downregulation of TGF- $\beta 1$ expression. Taken together, these results demonstrated that OM markedly inhibited the Smad2 phosphorylation and the formation
A
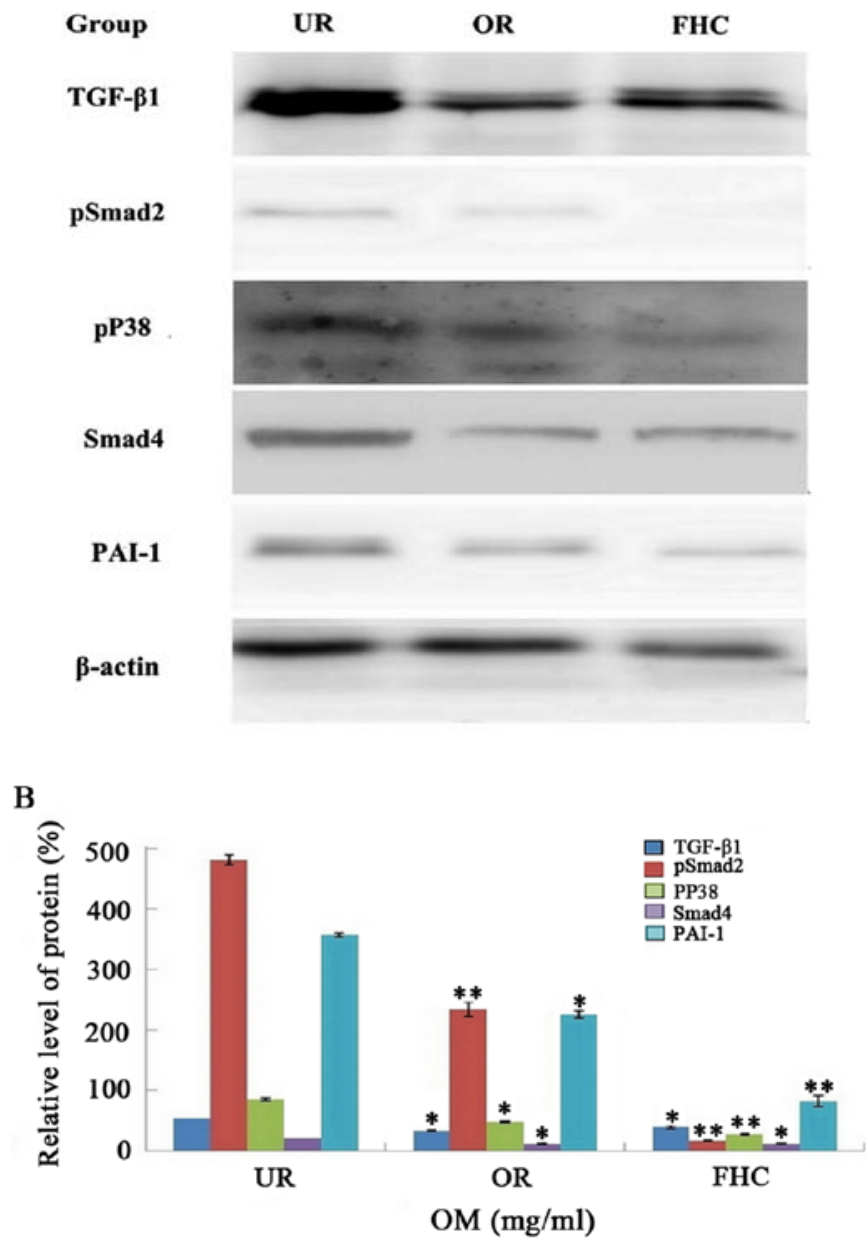

Figure 5. Effect of oxymatrine (OM) on the expression of TGF- $\beta 1$, pSmad2, PP38, Smad4 and PAI-1 proteins by western blotting. Western blotting demonstrated that the expression levels of TGF- $\beta 1$ and PAI- 1 protein were markedly increased in the UR group as compared to the FHC group. The expression of TGF- $\beta 1$ and PAI-1 proteins was significantly decreased in the OR group as compared to the UR group. Western blotting also demonstrated that the expression level of Smad4 and the phosphorylation of Smad2 and P38 were markedly increased in the UR group as compared to the FHC group. The expression level of Smad4 and the phosphorylation of Smad2 and P38 were significantly decreased in the OR group as compared to the UR group. ${ }^{*} \mathrm{P}<0.05,{ }^{* *} \mathrm{P}<0.01$.

of Smad2/3/4 induced by TGF- $\beta 1$ and eventually reduced the protein and mRNA levels of PAI-1.

Effect of OM on the expression of P38 in RKO cells. Previous studies have found that P38 is associated with PAI-1 proteins in their free forms, as well as when they are bound to TGF- $\beta 1$. P38 had a positive correlation with PAI-1 between the UR group and FHC group, which suggests that the RKO cells exhibited increased PAI-1 expression perhaps through the P38 and OM-mediated downregulated PAI-1 expression perhaps by inhibiting P38 expression. To further investigate the molecular mechanisms involved in OM-inhibited EMT in RKO cells, we treated the RKO cells with SB203580 (a p38 MAPK inhibitor). Then western blotting was used to detect the protein levels of pSmad2 and PAI-1. Western blotting showed that SB203580 inhibited pSmad 2 and the expression of PAI-1 induced by 
A

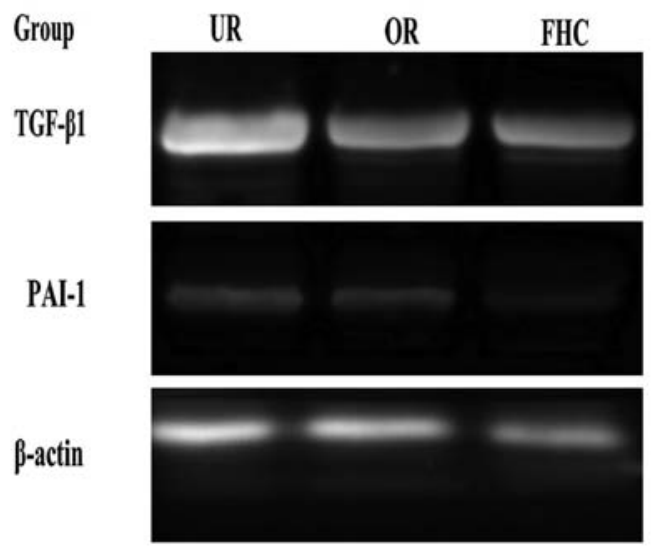

B

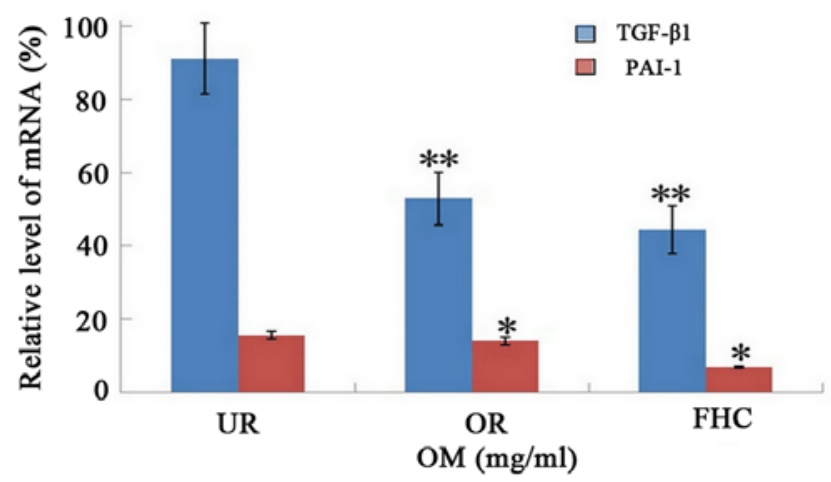

Figure 6. Effect of oxymatrine (OM) on the expression of TGF- $\beta 1$ and PAI- 1 by RT-PCR. RT-PCR demonstrated that the mRNA expression levels of TGF- $\beta 1$ and PAI- 1 were markedly increased in the UR group as compared to the FHC group. The mRNA expression levels of TGF- $\beta 1$ and PAI- 1 were significantly decreased in the OR group as compared to the UR group. The result was consistent with the protein expression level in each group. ${ }^{*} \mathrm{P}<0.05$, ${ }^{* *} \mathrm{P}<0.01$.

TGF- $\beta 1$ as compared to the RKO cells (Fig. 7). The results suggest that $\mathrm{P} 38$ regulates the phosphorylation of $\mathrm{Smad} 2$ and the synthesis of the Smad2/3/4 compound. Taken together, these results demonstrated that the protein expression and transcriptional activity of PAI-1 were regulated by the TGF- $\beta 1$ signaling pathway via P38. Moreover, these results suggest that $\mathrm{OM}$ inhibits the protein expression and transcriptional activity of PAI-1 via inhibiting the increase in P38 induced by the TGF- $\beta 1$ signaling pathway.

\section{Discussion}

Tumor metastasis is the principal cause of the mortality of colorectal cancer patients, and is also a key factor determining the extent of colorectal cancer progression (10). TGF- $\beta 1$, as a fundamental mediator of ECM, plays a critical role in the EMT process by a Smad-dependent pathway, resulting in tumor metastasis (18). Smad2 proteins are phosphorylated by the TGF- $\beta 1$ receptor and mediate the intracellular signal transduction of TGF- $\beta 1$ (21).

PAI-1 is not only a rapid and specific inhibitor of the plasminogen/plasmin system, but is a potent regulator of tumor growth in vivo. Increased PAI-1 has been confirmed in many
A

Group

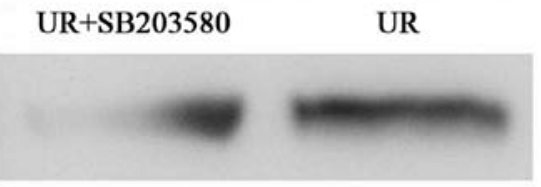

PAI-1

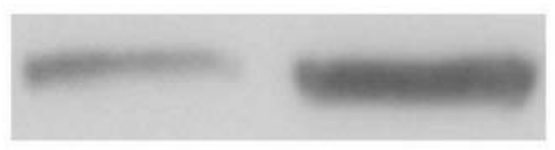

$\beta$-actin

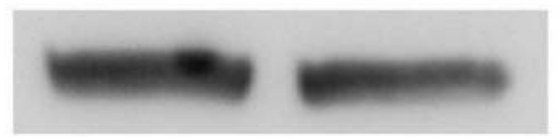

B

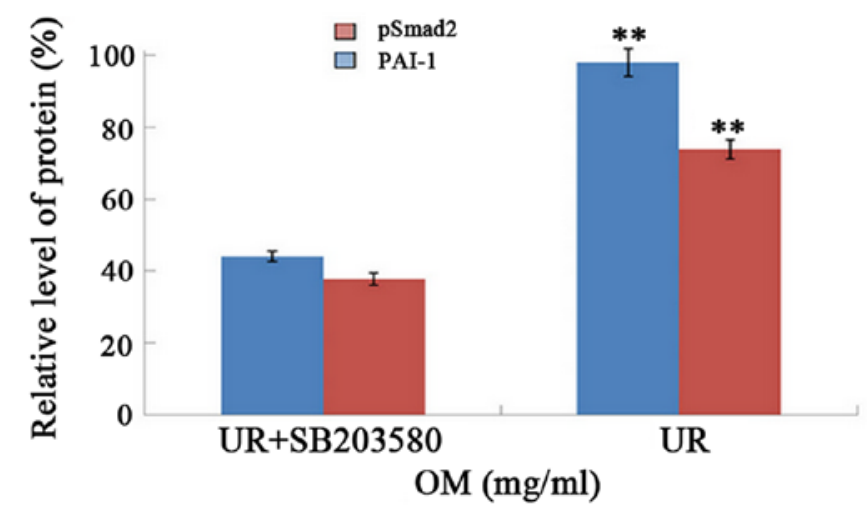

Figure 7. Effect of SB203580 (a p38 MAPK inhibitor) on the expression of pSmad 2 and PAI-1 proteins by western blotting. Western blotting demonstrated that the expression level of PAI-1 and the phosphorylation of Smad2 were markedly inhibited by SB203580 as compared to the UR group. ${ }^{* * *} \mathrm{P}<0.01$.

solid tumors and was found to be associated with a poor prognosis in several human cancers including colorectal cancer. Thus, PAI-1 has been an attractive potential target for various cancers. Recent studies have demonstrated that the expression of TGF- $\beta 1$ was significantly increased, while the expression of PAI-1 was significantly increased in colorectal tissues from patients with colorectal cancer, resulting in the persistent activation of the TGF- $\beta 1 /$ Smad pathway $(19,20)$. This activation leads to the induction and promotion of EMT in colorectal cancer cells and the subsequent onset of tumor metastasis. Similarly, these studies have shown that the expression of E-cadherin (a marker for epithelial cells) was significantly reduced, while the expression of $\alpha$-SMA (a marker for mesenchymal cells) and FN (an important component of ECM) were significantly increased. The mRNA and protein levels of TGF- $\beta 1$ and PAI- 1 were markedly increased in the colorectal cancer cells. These results suggest that EMT was induced and promoted in colorectal cancer by elevating the expression of TGF- $\beta 1$ and PAI- 1 .

In the present study, the protein and mRNA levels of PAI-1 were upregulation in the colorectal cancer cells, which implied that the expression of PAI-1 was regulated at the transcriptional level, including the P38 gene. P38 is recognized as an important positive regulating factor of the TGF- $\beta 1 / \mathrm{Smad}$ signaling pathway, which promotes activation of TGF- $\beta 1$ target genes 
and enhances the biological effects of the TGF- $\beta 1 / \mathrm{Smad}$ signaling pathway by interacting with Smad proteins (22). Furthermore, we performed in vitro western blotting assay and found that SB203580, a p38 MAPK inhibitor, markedly inhibited the expression of PAI-1.

As an important regulator, P38 modulates signaling pathways. P38 promotes activation of the TGF- $\beta 1$ signaling pathway. Once TGF- $\beta 1$ signaling is activated, P38 binds to $\mathrm{pSmad} 2 / 3$ and induces upregulation of $\mathrm{Smad} 2 / 3 / 4$. In the present study, the expression of P38, pSmad2 and PAI-1 was significantly increased in the RKO cells, demonstrating that TGF- $\beta 1 /$ Smad promotes the P38-mediated increased expression of PAI-1 mRNA mediated by $\mathrm{p}-\mathrm{Smad} 2 / \mathrm{Smad} 3$.

$\mathrm{OM}$ is a traditional Chinese herbal product. As the main active component of Sophora flavescens Ait, OM has multiple pharmacological effects and functions. OM was found to attenuate EMT of hepatocellular carcinoma and pulmonary carcinoma via inhibiting the TGF- $\beta 1 /$ Smad signaling pathway (23). However, it is not known whether OM can attenuate EMT of colorectal carcinoma in the development of tumor metastasis. Our findings showed that OM reversed the marked decrease in E-cadherin and significantly increased $\alpha$-SMA, FN, TGF- $\beta 1$, pSmad2, Smad2/3/4 and P38 and attenuated the P38-dependent increased expression of PAI-1 induced in colorectal cancer, which indicates that OM can inhibit EMT in colorectal cancer via inhibiting the TGF- $\beta 1 /$ Smad signaling pathway by reducing P38-dependent increased expression of PAI-1. Hence, OM could be a novel therapeutic agent for colorectal cancer.

\section{References}

1. Yuan X, Sun Y, Miao N, Sun S, Wang Y, Hu Z, Yuan J, Xu M and Liu Z: The synergistic anti-inflammatory effect of the combination of sodium ferulate and oxymatrine and its modulation on inflammation-associated mediators in RAW 264.7 cells. J Ethnopharmacol 137: 1477-1485, 2011.

2. Chen X, Sun R, Hu J, Mo Z, Yang Z, Liao D and Zhong N: Attenuation of bleomycin-induced lung fibrosis by oxymatrine is associated with regulation of fibroblast proliferation and collagen production in primary culture. Basic Clin Pharmacol Toxicol 103: 278-286, 2008.

3. Fan H, Chen R, Shen L, Lv J, Xiong P, Shou Z and Zhuang X: Oxymatrine improves TNBS-induced colitis in rats by inhibiting the expression of NF-kappaB p65. J Huazhong Univ Sci Technolog Med Sci 28: 415-420, 2008.

4. Zhao P, Zhou R, Li HN, Yao WX, Qiao HQ, Wang SJ, Niu Y, Sun T, Li YX and Yu JQ: Oxymatrine attenuated hypoxicischemic brain damage in neonatal rats via improving antioxidant enzyme activities and inhibiting cell death. Neurochem Int 89: 17-27, 2015.

5. Guzman JR, Koo JS, Goldsmith JR, Mühlbauer M, Narula A and Jobin C: Oxymatrine prevents NF- $\kappa \mathrm{B}$ nuclear translocation and ameliorates acute intestinal inflammation. Sci Rep 3: 1629, 2013.

6. Guo C, Han F, Zhang C, Xiao W and Yang Z: Protective effects of oxymatrine on experimental diabetic nephropathy. Planta Med 80: 269-276, 2014.

7. Li J, Jiang K and Zhao F: Oxymatrine suppresses proliferation and facilitates apoptosis of human ovarian cancer cells through upregulating microRNA-29b and downregulating matrix metalloproteinase-2 expression. Mol Med Rep 12: 5369-5374, 2015.
8. Fei ZW, Qiu MK, Qi XQ, Dai YX, Wang SQ, Quan ZW, Liu YB and Ou JM: Oxymatrine suppresses proliferation and induces apoptosis of hemangioma cells through inhibition of HIF-1a signaling. Int J Immunopathol Pharmacol 28: 201-208, 2015.

9. Narayana Moorthy NS, Ramos MJ and Fernandes PA: Human ether-a-go-go-related gene channel blockers and its structural analysis for drug design. Curr Drug Targets 14: 102-113, 2013.

10. Wang X, Wang J, Wang Z, Wang Q and Li H: Dynamic monitoring of plasma amino acids and carnitine during chemotherapy of patients with alimentary canal malignancies and its clinical value. Onco Targets Ther 8: 1989-1996, 2015.

11. Tomida C, Aibara K, Yamagishi N, Yano C, Nagano H, Abe T, Ohno A, Hirasaka K, Nikawa T and Teshima-Kondo S: The malignant progression effects of regorafenib in human colon cancer cells. J Med Invest 62: 195-198, 2015.

12. Ma X, Yan W, Dai Z, Gao X, Ma Y, Xu Q, Jiang J and Zhang S: Baicalein suppresses metastasis of breast cancer cells by inhibiting EMT via downregulation of SATB1 and Wnt/ $\beta$-catenin pathway. Drug Des Devel Ther 10: 1419-1441, 2016.

13. Wind T, Jensen JK, Dupont DM, Kulig P and Andreasen PA: Mutational analysis of plasminogen activator inhibitor-1. Eur J Biochem 270: 1680-1688, 2003.

14. Tong Q, Weaver MR, Kosmacek EA, O'Connor BP, Harmacek L, Venkataraman $S$ and Oberley-Deegan RE: MnTE-2-PyP reduces prostate cancer growth and metastasis by suppressing p300 activity and $\mathrm{p} 300 / \mathrm{HIF}-1 / \mathrm{CREB}$ binding to the promoter region of the PAI-1 gene. Free Radic Biol Med 94: 185-194, 2016.

15. Lampelj M, Arko D, Cas-Sikosek N, Kavalar R, Ravnik M, Jezersek-Novakovic B, Dobnik S, Dovnik NF and Takac I: Urokinase plasminogen activator (uPA) and plasminogen activator inhibitor type-1 (PAI-1) in breast cancer - correlation with traditional prognostic factors. Radiol Oncol 49: 357-364, 2015.

16. Deepak V, Ramachandran S, Balahmar RM, Pandian SR, Sivasubramaniam SD, Nellaiah $\mathrm{H}$ and Sundar K: In vitro evaluation of anticancer properties of exopolysaccharides from Lactobacillus acidophilus in colon cancer cell lines. In Vitro Cell Dev Biol Anim 52: 163-173, 2016.

17. Langenskiöld M, Holmdahl L, Angenete E, Falk P, Nordgren S and Ivarsson ML: Differential prognostic impact of uPA and PAI-1 in colon and rectal cancer. Tumour Biol 30: 210-220, 2009.

18. Zong W, Yu C, Wang P and Dong L: Overexpression of SASH1 inhibits TGF- $\beta 1$-induced EMT in gastric cancer cells. Oncol Res 24: 17-23, 2016.

19. Vayalil PK, Iles KE, Choi J, Yi AK, Postlethwait EM and Liu RM: Glutathione suppresses TGF-beta-induced PAI-1 expression by inhibiting p38 and JNK MAPK and the binding of AP-1, SP-1, and Smad to the PAI-1 promoter. Am J Physiol Lung Cell Mol Physiol 293: L1281-L1292, 2007.

20. Goto N, Hiyoshi H, Ito I, Iida K, Nakajima Y, Nagasawa K and Yanagisawa J: Identification of a novel compound that suppresses breast cancer invasiveness by inhibiting transforming growth factor- $\beta$ signaling via estrogen receptor $\alpha$. J Cancer 5: 336-343, 2014.

21. Argentou N, Germanidis G, Hytiroglou P, Apostolou E, Vassiliadis T, Patsiaoura K, Sideras P, Germenis AE and Speletas M: TGF- $\beta$ signaling is activated in patients with chronic HBV infection and repressed by SMAD7 overexpression after successful antiviral treatment. Inflamm Res 65: 355-365, 2016.

22. Jiang Y, Wu C, Boye A, Wu J, Wang J, Yang X and Yang Y: MAPK inhibitors modulate Smad2/3/4 complex cyto-nuclear translocation in myofibroblasts via Imp7/8 mediation. Mol Cell Biochem 406: 255-262, 2015.

23. Liu L, Wang Y, Yan R, Li S, Shi M, Xiao Y and Guo B: Oxymatrine inhibits renal tubular EMT induced by high glucose via upregulation of SnoN and inhibition of TGF- $\beta 1 / \mathrm{Smad}$ signaling pathway. PLoS One 11: e0151986, 2016. 